\title{
SUSTAINABLE APPROACHES TO REDUCE CARBON FOOTPRINT IN TEXTILE PROCESSING INDUSTRY
}

\section{DR. SWARNIMA SINGH, DIVYA SINGHAL \& RUCHIKA}

Amity School of Fashion Technology, Amity University, Greater Noida, Amity University, Uttar Pradesh, India

\begin{abstract}
Carbon Footprints are the amount of the carbon dioxide which is generated and released by an activity of any individual, community or industry. The apparel and textile processing industry is one of the largest industry which generates Green House Gases like Carbon Dioxide, Methane, Nitrous Oxide and Fluorocarbons and accounts for a significant amount of Carbon Footprint leading to global warming.
\end{abstract}

The US Energy Information Administration data reveals that the Textile industry is the $5^{\text {th }}$ biggest and major contributor to COzemissions. So is the Indian Textile Industry, currently estimated US\$150 billion and expecting to reach US\$250billion by 2020 will be a major contributor of carbon footprint.

To achieve this target, huge amounts of water and fuel (to generate electricity, steam and transportation) is required. This will directly contribute to enhance carbon footprint. Beside this, there will be requirements of huge quantity of dyes, chemical and auxiliaries, which further increase effluent load. The huge amount of fossil fuel consumed during processing of textiles having carbon content results in acidification, fossil fuel depletion and results in global warming that again leads to carbon footprint generation.

Therefore, to combat this alarming situation of environmental pollution and to reduce carbon footprints the textile industry needs to incorporate sustainable approach

The carbon footprints can be reduced during the whole textile processing due to minimum water consumption, reducing m:l ratio, using sustainable chemicals, and moving towards a green gas instead of coals, recycling of water, solar energy etc.

This paper suggests some sustainable approaches which can be used to reduce the carbon footprints during the whole textile wet processing.

KEYWORDS: Carbon Footprints, Carbon Dioxide, Greenhouse Effect, Sustainable Approach \& Textile Industry

Received: Jun 02, 2020; Accepted: Jun 22, 2020; Published: Aug 03, 2020; Paper Id.: IJTFTAUG20206

\section{INTRODUCTION}

Global warming has become a major problem of the world which needs immediate attention. The greenhouse gases released in the environment are so dangerous and harmful that if not addressed immediately, the damages done to the environment will be irreparable. These gases responsible for environment warming are named as greenhouse gases (GHG), Carbon Dioxide, Methane, Nitrous Oxide and Fluorocarbons are the major contributors. 
Basically, carbon footprint is the amount of carbon released into environment depending upon the power and fuel consumptions.

In the value chain of a product the carbon footprint is disclosed by the $\mathrm{CO}_{2}$ liberated in the atmosphere. Carbon dioxide, being one of the main cause and contributor of global warming, accounts about 80 percent of emissions through industrialization.

Climate change, which we are experiencing, can be attributed to the after effect of our activities resulting into carbon footprint. It has a great impact on our daily lives because of the carbon footprint generated by burning fossil fuel for power and heat.

Activities with a high carbon footprint contain substantial quantities of greenhouse gases and thus have a huge eff ect onthe atmosphere.

The Carbon footprint is evaluated in two layers:

- Primary footprint, which is a measure of carbon pollution directly generated from the use of energy by burning fossil fuels for power, heating, transport, etc. In this case, we have direct control on emissions.

- Secondary footprint, which is the indirect emissions of carbon dioxide over the whole life cycle of the products we use.

The term product lifecycle covers the entire period from the time the raw materials are farmed, manufactured until they are disposed of.

\section{Greenhouse Gases and Climate Change}

As human produced greenhouse gases cumulate, and their concentration in the environment increases, it tends towards climate warming.

Carbon dioxide, which is the main donor of climate warming in atmosphere, is almost 80 percent of the total emissions of all developed industries of the world.

The pace at which carbon dioxide is emitted is also escalating with increasing population and growing demands fo $\mathrm{r}$ transport and electricity.

Many greenhouse gases resulting from industrial and agricultural processes include:

- Methane

- Nitrous oxide

- Hydrofluorocarbons (HFCs)

- $\quad$ Perfluorocarbons (PFCs)

- Sulphur hexafluoride (SF6)

The major change that occurs is rise in temperature. Climate forecasts expect a global temperature increase of 1.4 
to $5.8^{\circ} \mathrm{C}$ by 2100 , if the current trends in warming remain ungovernable.

This is expected to cause such catastrophic events as:

- Low lying coastal areas flooded

- Northern hemisphere climate changes with wetter, cooler winters and warm dryer summers.

- $\quad$ Extreme weather worldwide, with frequent storms, droughts and heavy rainfall.

\section{REVIEW OF LITERATURE}

Impact of carbon footprints has been a major concern for all environmentalists all over the world. Lot of work has been done to reduce the impact of carbon footprints in all aspects. Textile is the second major polluter of the environment and produces lot of greenhouse gases while textile processing. The textile companies are now focusing to reduce the carbon footprints into the environment.

Levi Strauss \& Co. (2009a, 2009b) licensed two of its key products to an LCA.

By taking a product life-cycle prospective to their work, they have been able to establish a range of approaches to tackle the major environmental influence of their occupation [1].

Based on the projections and the assumptions made, the carbon footprint of the related textile industry is expected to be rising year by year.

In 2010 the carbon footprint reached 20436.615167 tCO2e while in 2014 it was almost 42867.72 tCO2e i.e. the e missions nearly doubled in a five-year period.

As regards scopes, it is witnessed that over the five years, scope 1 emissions have endured as the largest donor to the total carbon footprint [2].

Textile Industry will have to pay the attention on the case studies done by many company Wiedmann and Minx (2007)[3] considering that $4 \%$ of the total secondary carbon footprint in the industrialized countries is contributed by apparel and textiles individually.

McCurry (2009) [4] expressed in a study on future trends in the textile industries conducted by Freedonia Group, a consultancy firm based in Ohio.

The study said the companies will pay heed to a host of climatic issues aimed at reducing their carbon footprints and environmental footprints.

Herva et al. (2008) has proposed an ecological footprint study on the textile sector[5].

They analyzed a textile tailoring plant with the overall purpose of developing a tool to assess the climaticinfluence evolution due to plant production and to compare the environmental behavior of various tailoring processes. These processes to the production of greenhouse gases.

In fact, greenhouse gases find their way through the atmosphere by various activities in which the industries participate. Industrialization is increasing at a higher rate in this era of largely distributed population.

Therefore, greenhouse gas concentrations are predicted to be even high in the atmosphere (Gillen 2012). 
Growth in industrialisation and development has made atmospheric GHGs clear. Nearly all the facilities contribut e to some degree of polluting the atmosphere, whether on a minor or major basis. In this regard even the textile sector plays its role (Parry et al. 2007). [7]

All these processes produces greenhouse gases. Industries and companies are responsible for the amount of greenhouse gases and carbon dioxide presence in climate. Industrialization in this period of majorly dispersed inhabitants is going high at a massive rate. Hence, the concentrations of greenhouse gases into the climate are expected to be even more elevated. (Gillen 2012). [6] The growth of industrialization and the automation has made GHGs present in the climate. Nearly all the resources are according in poisoning the airspace to some stretch whether on a minor or major basis. Beside textile sector is also playing its role in this view. (Parry et al. 2007). [7]

\section{RESEARCH METHODOLOGY}

This paper is based on secondary data sourced from various journals, books, articles. Basically, analytical research is used in which existing data is collected and analysed. In this study basically the problem of pollution of environment is dealt in terms of carbon foot print released and it's after effect and critical evaluation is done. A detailed analysis is done of the carbon footprints effects of the textile industry on the environment, the ways to deal with the problem and how to control the release of the carbon footprints?

\section{Carbon Foot Print in Textile Industry}

Given that uncountable processes and products- which are involved into the making of any clothing or products by the current textile industry-are the main reason and cause of greenhouse gases, it is estimated that clothing and textiles produced by the textile industry counts for about 4 percent of total secondary carbon footprint. It is well known that substantial amount of chemicals and water is used by textile industry. Major amounts of fossil fuels which have carbon content and react with oxygen to form carbon dioxide are consumed during the wet treatment process. This makes for acidi fication, depletion of fossil fuel and, lastly, climate warming. Lots of energy is required to produce fabrics. The approximate energy and water needed to generate that amount of fabric boggles themind: 1.074 billion KWh of electri city (or 132 million metric tons of coal) and 6 trillion liters of water in between. Textiles and apparel generally account for around four per cent of an individual's secondary carbon footprint in the developedworld according to estimates.

Every year, more than 1 million tons of textiles are thrown away, of which $50 \%$ can be recycled. Such wastes requ ire a landfill, as they don't easily decompose. While decomposing, methane gas is generated by woolen garments, leading to global warming. Clothing is responsible for around one ton of $\mathrm{CO}_{2}$ emissions(including washing and drying).

Research has shown that machine washing and drying can cause about 75 per cent of the carbon footprint of the $\mathrm{T}$ -shirt over its lifecycle.

It's unbelievable but true that fabrics adds to a huge amount of carbon footprint to the environment consuming energy in bulk for producing fabrics.US textile industry is the $5^{\text {th }}$ largest contributor of $\mathrm{CO}_{2}$ emissions, as per U.S. Energy Information Administration, after primary metals, non-metallic mineral products, petroleum and chemicals. In the developing world where textile industry counts for larger amount of $\mathrm{CO}_{2}$ emission, and adds to the major percentage of GDP, it is found that mills are mostly antiquated.

Due to its enormous sizes and scope and extensive amount of the products being made, processed and finished by 
it, the textile industry accounts for major source of greenhouse gases produced on Earth.

Based on an projected annual global textile demand of 60 billion kilograms (KG)

of of cloth, the expected energy and water needed to manufacture 60 billion kilograms of fabrics boggles the mind: $1.074 \mathrm{~b}$ illion kWh of electricity (or 132 million metric tons of coal) and between $6-9$ trillion liters of water.

\section{Reducing Carbon Footprints to Maintain Sustainability}

The garment industry is highly water consuming. Water is used throughout the entire production for cleaning up the raw $\mathrm{m}$ aterial and for many flushing steps. The waste water produced must be washed from fat, oil, color and other chemicals whi ch are used during the various steps of production. Throughout the operations of textile processing water is used extensively.Mostly all chemicals, dyes and finishing chemiclas are used through water medium, only using water baths.All pre-process such as desizing, scouring, bleaching and mercerization are basically done through aqueous medium only.

The quantity of water used varies greatly in the industry, depending on the different procedures at the mill, the ma chinery used and the prevalent water usage management methodology. As one of the leading water users, it is one of the to $\mathrm{p}$ ten water user sectors.

Table 1: Water Consumption by Textile Industry in Various Processes

\begin{tabular}{|c|c|c|}
\hline S No. & Substrate & Water Consumption (kg/kg of Fabric) \\
\hline 1 & Cotton & $250-350$ \\
\hline 2 & Wool & $200-300$ \\
\hline 3 & Nylon & $125-150$ \\
\hline 4 & Rayon & $125-150$ \\
\hline 5 & Polyester & $100-200$ \\
\hline 6 & Acrylic & $100-200$ \\
\hline
\end{tabular}

https://textilelearner.blogspot.com/2014/04/water-consumption-in-textile-industry.html

Table 2: Water Consumption by Textile Industry in Various Processes

\begin{tabular}{|c|l|c|}
\hline S No. & \multicolumn{1}{|c|}{ Process } & $\begin{array}{c}\text { Water Consumption } \\
\text { (\% of Total) }\end{array}$ \\
\hline 1 & Bleaching, Finishing & 38 \\
\hline 2 & Dyeing & 16 \\
\hline 3 & Printing & 8 \\
\hline 4 & Boiler House & 14 \\
\hline
\end{tabular}

https://textilelearner.blogspot.com/2014/04/water-consumption-in-textile-industry.html 
Therefore, the textile industry needs recheck its strategies to diminish carbon footprints in textile wet processing and maintain sustainability following the compliancerulrs laid down by the environmental agencies. Du Pont, which invented all manmade fibers such as nylon, rayon and spandex is also into sustainability and has developed a new fiber named sorona which is made from agricultural feedstock. Revolutionary dyeing techniques which require less water than conventional techniques must be used. In conventional method, water is used to transport the fabric but in new technique air is used, which automatically reduces water consumption. The revolutionary air technology requires 50 liters of water to produce one t-shirt, wherein the conventional technology used to 200 liters of water. Instead of using conventional dyeing and printing methods, digital printing can be used. Digital printing is environment friendly as wastage of fabric and dyes in less and it does not requires salt as it's used like ink in printers, so it's more sustainable. The Indian textile industry has been ignorant towards the problem of carbon footprints. Conventional fibers should be replaced by organic fibers to reduce carbon footprints. In textile wet processing up to 2000 chemicals are used out of which few are evaporated and some are discharged in water. It should be replaced by the biodegradable enzymes.

Wastewater treatment is another area which needs immediate attention as the textiles processing (Finishing, dyeing and printing) consumes huge amount of water which results in a release of considerable amount of wastewater. Physical, biological and activated carbon system should be used to reduce wastage of water. End -of- pipe technology including various applications such as coagulation / flocculation, flotation, adsorption, evaporation, oxidation, combustion, use of membranes should be utilised for wastewater treatment.

\section{CONCLUSIONS}

The carbon footprint released by the global textile industry has become a major threat for the environment. It is well known that textile processing is the greatest consumer of fresh water required for the finishing, dyeing and printing which in turn releases great amount of polluted water. The time has come to look for more scientific methods to reduce the wastage of water, developing waste water treatment and reuse of the sludge produced. The Indian textile Industry is oblivious towards cleaner and greener environment. The need of an hour is to pay immediate attention towards sustainability. The whole world is moving towards a cleaner and greener process and a complete paradigm shift is seen. Therefore if we have to sustain and thrive more sustainable approach is required for future.

\section{REFERENCES}

1. Levi Strauss \& Co., 2009a. A product lifecycle approach to sustainability. Available from: www.levistrauss.com [Accessed June 2009].

2. Levi Strauss \& Co., 2009b. Carbon Disclosure Project CDP 2009 (CDP7). Available from: www.levistrauss.com [Accessed June 2009].

3. SanaAkhtar,Shahzeen Fatima Baig,SamiaSaif, SamiaSaifand Sajid Rashid Ahmad, 2017,Five Year Carbon Footprint of a Textile Industry: A Podium to incorporateSustainability.pp. 125-132.

4. Wiedmann, T. and Minx, J., 2007. A definition of carbonfootprint. ISAUK Research Report.

5. McCurry, J., 2009. Environment to impact on demand. International Dyer, 194 (2), 9.

6. Ahmed, A. Kaleel, C. B. Senthilkumar, and S. Nallusamy. "Study on environmental impact through analysis of big data for sustainable and green supply chain management." Int. J. Mech. Prod. Eng. Res. Dev. 8 (2018): 1245-1254.

7. Herva, M., et al., 2008. An approach for the application of theecological footprint as environmental indicator in the textilesector. 
Journal of Hazardous Materials, 156 (1-3), 478-487.

8. Gillen, M. 2012. What is wrong with 'real' carbon offsets? GreenhouseGas Measurement and Management, 2(4): 167-170.

9. Bhalla, Rupa, and P. O. O. J. A. Mehta. "Green Hr: The Essence for Sustainability in the 21st Century." International Journal of Human Resource Management and Research (IJHRMR) 6.1 (2016): 1-6.

10. Parry, M.L. Canziani, O.F. Palutikof. J.P. and Van der Linden, C.E.2007. Adaptation and Vulnerability. Contribution of Working

11. Group II to the Fourth Assessment Report of the IntergovernmentalPanel on Climate Change, 976.

12. Aranganathan, P. "GREEN RECRUITMENT: A NEW-FANGLED APPROACH TO ATTRACT AND RETAIN TALENT." International Journal of Business Management and Research (IJBMR) 8.2 (2018): 69-76.

13. Carbon footprint of textiles, https://www.domain-b.com/environment/20090403_carbon_footprint.html

14. https://textilelearner.blogspot.com/2014/04/water-consumption-in-textile-industry.html

15. Sangode, PALLAWI B., and SUJIT G. Metre. "Gren supply chain practices for environmental sustainability: a proposed framework for manufacturing firms." International Journal of Mechanical and Production Engineering Research and Development (IJMPERD) 9.2 (2019): 287-298.

16. Jain Meenakshi,Ecological approach to reduce carbon footprint oftextile industry, Volume 4 (7\&8), July \& August (2017) p.623633

17. https://oecotextiles.wordpress.com/2009/05/25/carbon-footprint-of-the-textile-industry/

18. Ashok Athalye, Carbon Footprint in TextileProcessing, www.fibre2fashion.com.

19. Faisal Bin Alam .Md Arafat Hossain, "Conservation of Water resources in Textile and Apparel Industries"IOSR Journal of polymer and Textile Engineering(IOSR-JPTE),Volume5,Issue 5(Sep-Oct 2018),PP 11-14 
